\title{
Eficácia de Chenopodium ambrosioides (erva-de-santa-maria) no controle de endoparasitos de Coturnix japonica (codorna japonesa) ${ }^{1}$
}

\author{
Gilmar F. Vita ${ }^{2 *}$, Ildemar Ferreira ${ }^{2}$, Maria Angélica V. da Costa Pereira ${ }^{3}$, Argemiro \\ Sanavria $^{4}$, Rita de Cássia M. Aurnheimer ${ }^{5}$, Celso G. Barbosa ${ }^{6}$, Samira S.M. Gallo ${ }^{3}$ \\ e Henrique V.G. Vasconcellos ${ }^{3}$
}

\begin{abstract}
Vita G.F., Ferreira I., Da Costa Pereira M.A.V., Sanavria A., Aurnheimer R.C.M., Barbosa C.G., Gallo S.S.M. \& Vasconcellos H.V.G. 2015. [Effectiveness of Chenopodium ambrosioides (santa maria herb) for controlling Coturnix japonica (japanese quail) endoparasites.] Eficácia de Chenopodium ambrosioides (erva-de-santa-maria) no controle de endoparasitos de Coturnix japonica (codorna japonesa). Pesquisa Veterinária Brasileira 35(5):424-430. Programa de Pós-Graduação em Biologia Animal, Departamento de Zoologia, Instituto de Biologia, Universidade Federal Rural do Rio de Janeiro, BR-465 Km 7, Seropédica, RJ 23890-000, Brazil. E-mail: gilmarferreiravita@yahoo.com.br

The aim was in vitro and in vivo to test the effectiveness of Chenopodium ambrosioides Linnaeus, 1786 (santa maria herb) medicinal plant, in regard to phytotherapeutic and homeopathic forms as alternative methods to control Coturnix japonica Temminck \& Schlegel, 1849 (japanese quail) endoparasites. The parasitosis is a serious problem affecting domestic poultry raising and performance causing death, delay in grow, food conversion rate reduction and increase of susceptibility to infectious diseases. Methodologies were advocated by Coles et al. (1992), corroborated by World Association for the Advancement of Veterinary Parasitology (WAAVP). Presence of the genera Ascaridia and Eimeria was displayed by this survey. In vitro essay demonstrated high reduction rate on eggs eclosion inhibition of Ascaridia sp. (100.00\%) and significant reduction rate on oocyst destruction of Eimeria sp. (47.06\%). In vivo essay demonstrated high fecal egg counting reduction rate of Ascaridia sp. (100.00\%) and expressive fecal oocyst counting reduction rate of Eimeria sp. (60.33\%). C. ambrosioides showed upper rates front traditional product (Thiabendalol/ Mebendazol) as well as to those ones advocated by the Brazilian Ministry of Agriculturel and the World Health Organization as effectiveness indicative.
\end{abstract}

INDEX TERMS: Chenopodium ambrosioides, Coturnix japonica, endoparasitosis.

\footnotetext{
${ }^{1}$ Recebido em 8 de novembro de 2014.

Aceito para publicação em 4 de maio de 2015.

${ }^{2}$ Programa de Pós-Graduação em Biologia Animal, Departamento de Zoologia, Instituto de Biologia, Universidade Federal Rural do Rio de Janeiro (UFRRJ), BR-465 Km 7, Seropédica, RJ 23890-000, Brasil. *Autor para correspondência: gilmarferreiravita@yahoo.com.br

${ }^{3}$ Setor de Parasitologia, Hospital Veterinário, Laboratório de Sanidade Animal, Universidade Estadual do Norte Fluminense Darcy Ribeiro (UENF), Av. Alberto Lamego 2000, Campos dos Goytacazes, RJ 28013-602, Brasil.

${ }^{4}$ Departamento de Epidemiologia e Saúde Pública, Instituto de Veterinária, Universidade Federal Rural do Rio de Janeiro (UFRRJ), BR-465 Km 7, Seropédica, RJ 23890-000.

${ }^{5}$ Centro Universitário Anhanguera, Rua Visconde do Rio Branco 137, Niterói, RJ 24020-001, Brasil.

${ }^{6}$ Departamento de Matemática, Instituto de Ciências Exatas, UFRRJ, BR465, Km 7, Seropédica, RJ 23890-000.
}

RESUMO.- 0 objetivo foi testar in vitro e in vivo a eficácia da planta medicinal Chenopodium ambrosioides Linnaeus, 1786 (erva-de-santa-maria), nas formas fitoterápica e homeopática, como meios alternativos para o controle de endoparasitos de Coturnix japonica Temminck \& Schlegel, 1849 (codorna japonesa), um sério problema que afeta a criação e desempenho de aves domésticas, ocasionando morte quando muito intenso, retardo de crescimento, redução de índice de conversão alimentar e aumento na suscetibilidade às doenças infecciosas. As metodologias utilizadas foram preconizadas por Coles et al. (1992), creditada pela World Association for the Advancement of Veterinary Parasitology (WAAVP). A pesquisa evidenciou a presença dos gêneros Ascaridia e Eimeria. 0 ensaio in vitro demons- 
trou alta taxa de redução na inibição de eclosão de ovos de Ascaridia sp. (100,00\%) e significativa taxa de redução na destruição de oocistos de Eimeria sp. (47,06\%). 0 ensaio in vivo demonstrou alta taxa de redução na contagem de ovos de Ascaridia sp. nas fezes (100,00\%) e expressiva taxa de redução na contagem de oocistos de Eimeria sp. nas fezes $(60,33 \%)$. Chenopodium ambrosioides mostrou em certos momentos superioridade frente ao produto tradicional (Thiabendazole/Mebendazole) e índices superiores aos preconizados pelo Ministério da Agricultura do Brasil e Organização Mundial da Saúde como indicativos de eficácia.

TERMOS DE INDEXAÇÃO: Chenopodium ambrosioides, Coturnix japonica, endoparasitoses.

\section{INTRODUÇÃo}

0 crescimento do setor da coturnicultura no Brasil é muito significativo. 0 país é o quinto produtor mundial de carne de codornas e o segundo em ovos, com um efetivo de criação de aproximadamente 15 milhões de indivíduos (IBGE 2011, Silva et al. 2011). Entre as vantagens oferecidas ao pequeno e médio produtor para sua criação está o rápido crescimento, alta produção, menor demanda espacial e baixo investimento (Martins 2002, Albino \& Barreto 2003).

Inúmeras patologias estão associadas à criação e desempenho de aves em cativeiro, e uma delas constantemente observada, é a infecção parasitária intestinal, que pode ocasionar retardo no crescimento, anemia, atrofia da musculatura peitoral, obstrução intestinal, perfuração de mucosas, aumento na suscetibilidade às doenças infecciosas e morte quando muito intensa (Back 2002, Cubas \& Godoy 2004, Galvão \& Pereira 2011).

Dentre as formas sugeridas para o tratamento das endoparasitoses aviárias, salientamos a utilização de plantas da "medicina popular". A fitoterapia e a homeopatia surgem como alternativas para promover esse controle, oferecendo aos criadores, uma metodologia limpa e sem maiores agravantes (Brito et al. 2009, Fernandes et al. 2009).

Terapias alternativas naturais para cura de enfermidades animais encontram-se em fase de investigação de eficácia. Testar produtos da flora medicinal, contrapondo-os frente aos tradicionais, e verificar sua eficiência sobre espécies que causam danos à saúde do animal, é uma contribuição de pesquisadores da área, e também conscientização da busca de novas opções, para os problemas que atualmente afligem a saúde de toda uma classe (Vita et al. 2014).

$\mathrm{O}$ objetivo do estudo foi testar in vitro e in vivo a eficácia da planta medicinal Chenopodium ambrosioides Linnaeus, 1786, erva-de-Santa-Maria, nas formas fitoterápica e homeopática, como meios alternativos para o controle de endoparasitos de Coturnix japonica Temminck \& Schlegel, 1849, codorna Japonesa.

\section{MATERIAL E MÉTODOS}

A pesquisa foi conduzida no Laboratório de Zoologia, Instituto de Biologia, Universidade Federal Rural do Rio de Janeiro (UFRRJ), localizado no município de Seropédica, estado do Rio de Janeiro, e Setor de Parasitologia Animal, Laboratório de Sanidade Animal, Hospital Veterinário, Centro de Ciências e Tecnologias Agropecu- árias, Universidade Estadual do Norte Fluminense Darcy Ribeiro (UENF), localizado no município de Campos dos Goytacazes, estado do Rio de Janeiro, no período de 2011-2012.

Foram realizados dois experimentos, um fitoterápico e outro homeopático, onde se avaliou a eficácia da planta com ensaio inicial in vitro, teste de inibição de eclosão de ovos/destruição de oocistos, e a posteriori in vivo, teste de redução da contagem de ovos/oocistos nas fezes.

O extrato das folhas de Chenopodium ambrosioides foi obtido comercialmente no Laboratório Dr. Faria E.M. Mello Ltda, sendo na forma fitoterápica como tintura mãe e na forma homeopática em baixa dinamização hahnemanniana (CH6), ambas diluídas em solução alcoólica a $70 \%$.

Nos experimentos fitoterápico e homeopático, tanto no ensaio in vitro ou in vivo, foram empregadas 36 codornas japonesas, com cinco semanas de vida e peso vivo médio de $140 \mathrm{~g}$, criadas em sistema intensivo, com infecção parasitária natural, sem administração prévia de anti-helmínticos (Coles et al. 1992).

As codornas foram originárias de uma granja situada na localidade de São Miguel, município de Seropédica, estado do Rio de Janeiro. As aves foram alojadas em gaiolas de arame galvanizado apropriadas ( $1 \mathrm{~m} \times 50 \mathrm{~cm} \times 20 \mathrm{~cm}$ ), com nove animais por gaiola. A alimentação constou de ração balanceada para postura, de 25 a $30 \mathrm{~g} /$ dia, e água ofertada ad libitum. A temperatura foi ambiente e a iluminação natural, sendo poupadas da luz direta do sol (SEBRAE 2006, SBRT 2007).

Para a coleta do material biológico, no dia da realização do teste, o piso sob a área das gaiolas foi previamente forrado com lona plástica às 5:00 horas da manhã, com recolhimento do material fecal às 6:00 horas. Este foi acondicionado em potes plásticos, devidamente identificados, mantidos sob refrigeração $\left(2\right.$ a $\left.8^{\circ} \mathrm{C}\right) \mathrm{e}$ encaminhados ao laboratório para realização das análises em no máximo três horas, a contar do momento em que se fez a forragem (Coles et al. 1992, OPAS 2010).

As metodologias utilizadas na pesquisa foram preconizadas por Coles et al. (1992), e embasadas pela World Association for the Advancement of Veterinary Parasitology (WAAVP), no próprio trabalho deste autor.

\section{Ensaio in vitro}

Foram realizados oito tratamentos, sendo três na forma fitoterápica, três na forma homeopática, um controle negativo e um controle positivo, com três repetições, em um delineamento inteiramente casualizado, totalizando 24 parcelas.

\section{Preparação da suspensão de ovos/oocistos}

1) $25 \mathrm{~g}$ de fezes com $200 \mathrm{ml}$ de água foram homogeneizadas com um agitador de laboratório. As amostras foram manuseadas em menos de três horas após a coleta.

2) A solução obtida foi passada para tigela através de tamis de malha $100 \mathrm{com} 20 \mathrm{~cm}$ de diâmetro (abertura de $0,15 \mathrm{~mm}$ ). 0 filtrado foi colocado em oito tubos de Clayton Lane.

3) Centrifugou-se por dois minutos a $1500 \mathrm{rpm}$, descartando-se após o sobrenadante.

4) Os tubos foram agitados para soltar o sedimento e, em seguida, solução saturada de cloreto de sódio foi adicionada até a formação de um menisco acima do tubo. Lamínulas foram colocadas sobre os tubos e a amostra foi centrifugada por dois minutos a $1000 \mathrm{rpm}$.

5) Cuidadosamente as lamínulas foram retiradas dos tubos e lavadas, sendo os ovos/oocistos deslizados para um tubo de centrífuga de vidro cônico, preenchido com água e centrifugado por dois minutos a $1500 \mathrm{rpm}$.

6) Novamente o sobrenadante foi removido e os ovos/oocistos ressuspendidos na água. 


\section{Procedimento do teste}

1) $2 \mathrm{ml}$ da suspensão de ovos/oocistos (menos de três horas anterior à coleta) foram colocados em poços de placa de cultivo com 24 cavidades.

2) $1 \mathrm{ml}$ do extrato da planta foi misturado com as seguintes diluições: 0,060ml:0,940ml H2O, 0,120 ml:0,880ml H2O e 200ml:0,800ml H2O.

3) No poço controle positivo foram adicionados $0,010 \mathrm{ml}$ de solução de Thiabendazole/Mebendazole (Neovermin ${ }^{\circledR}$ - Neo Química Brasil), conforme estabelecido pelo laboratório, aos $2 \mathrm{ml}$ da suspensão. 0 produto foi dissolvido em $0,990 \mathrm{ml}$ de metanol.

4) No poço controle negativo foram adicionados $1 \mathrm{ml}$ de água aos $2 \mathrm{ml}$ da suspensão.

5) Após permanência em BOD a $27^{\circ} \mathrm{C}$ por 48 horas, duas gotas de solução de Lugol's iodine foram adicionadas para parar a incubação dos ovos/proliferação dos oocistos.

6) Todos os ovos (mortos e embrionados), larvas recém-eclodidas e oocistos destruídos em cada poço foram contados. Foram realizadas três repetições para cada tratamento com extrato da planta e controle positivo e negativo.

\section{Ensaio in vivo}

1) Os animais foram distribuídos aleatoriamente em grupos controles negativo (água), positivo (Thiabendazole/Mebendazole) e tratados (fitoterápico e homeopático), em quatro gaiolas, com nove animais cada, conforme recomendação do Ministério da Agricultura, Pecuária e Abastecimento (1997) e Vercruysse et al. (2001).

2) Um mínimo de $30 \mathrm{~g}$ de fezes foi coletada de cada grupo.

3) As amostras foram conduzidas ao laboratório dentro do prazo estabelecido de três horas, para a contagem dos ovos/oocistos.

\section{Procedimento do tratamento}

1) Os animais foram tratados por três dias alternados, duas vezes ao dia. Quando do controle positivo (Thiabendazole/Mebendazole), por via oral, em mililitro por quilograma de peso, na dosagem de 0,300 ml para cada codorna, conforme estabelecido pelo fabricante, utilizando seringas descartáveis, e quando dos tratamentos homeopático e fitoterápico, por deposição em dois litros de água, na dosagem de $3 \mathrm{ml}$ para cada codorna, adequação proveniente da dose que apresentou maior eficácia no teste in vitro $(0,200 \mathrm{ml}$ produto $/ 0,800 \mathrm{ml} \mathrm{H} 20)$, e calculada com base no peso diário de alimento fornecido ao animal e consequentemente em trânsito gastrintestinal, assim sendo:

$\mathrm{DC}_{\text {invivo }}=\frac{\text { Dose mais eficaz no ensaio in vitro } \mathrm{x} \text { alimento diário ingerido }}{2^{*}}$

* $2 \mathrm{ml}$ (ou g) da suspensão de ovos/oocistos controlada pela dose mais eficaz no teste in vitro.

2) 12 dias após o tratamento, as amostras fecais foram coletadas e o número de ovos/oocistos novamente contados.

Procedimento da contagem de ovos/oocistos nas fezes (técnica de McMaster modificada)

1) Três gramas de fezes foram pesadas e colocadas em um recipiente de vidro de $250 \mathrm{ml}$.

2) $42 \mathrm{ml}$ de água foram adicionados, deixando de molho por 30 minutos, até que as fezes ficassem moles.

3) Homogeneizou-se com agitador magnético.

4) A solução foi passada para uma tigela através de tamis com malha de 100 e diâmetro de $20 \mathrm{~cm}$ (abertura de $0,15 \mathrm{~mm}$ ).

5) 0 líquido foi agitado e $13 \mathrm{ml}$ foi despejado em um tubo de centrífuga de $15 \mathrm{ml}$.
6) Centrifugou-se por dois minutos a 1500rpm e descartou-se o sobrenadante.

7) 0 tubo foi agitado para soltar o sedimento e foi adicionada solução saturada de cloreto de sódio para obter o mesmo volume de antes $(13 \mathrm{ml})$.

8) Inverteu-se o tubo seis vezes e imediatamente foi retirada uma amostra com uma pipeta Pasteur, preenchendo o primeiro compartimento da câmara de McMaster.

9) 0 processo de inversão foi repetido e o segundo compartimento foi preenchido.

10) Os ovos/oocistos foram visualizados em aumento de 40x, à luz da microscopia óptica, contando todos sob as duas grades (total volume de $2 \mathrm{ml}$ ).

11) Multiplicou-se o número de ovos/oocistos por 50 para obter o opg da amostra fecal.

Os endoparasitos encontrados foram identificados segundo chaves de identificação e características morfológicas estabelecidas por Vicente et al. (1995) e McDougald (1997), e observados à luz da microscopia óptica, com aumento de 10x, 40x e 100x.

A análise estatística dos dados obtidos das contagens parasitológicas foi realizada através da análise de variância (ANOVA) e complementada pelo teste de Tukey $(\mathrm{p}<0,05)$ (Vieira 2008).

Esta pesquisa foi submetida à Comissão de Ética na Pesquisa da Universidade Federal Rural do Rio de Janeiro, sob o número de processo 23083.008735/2012-56, ficando estabelecido que a mesma atende aos princípios básicos para pesquisa envolvendo o uso de animais e está de acordo com os princípios éticos e do bem estar animal, estabelecido pela Resolução 714 de 20/06/2002 do Conselho Federal de Medicina Veterinária.

\section{RESULTADOS}

Durante o desenvolvimento dos ensaios foram encontrados ovos de Ascaridia sp. e oocistos de Eimeria sp., de acordo com chaves de identificação e características morfológicas dispostas por Vicente et al. (1995) e McDougald (1997).

Os valores encontrados após a aplicação do ensaio in vitro na inibição de eclosão de ovos de Ascaridia sp. evidenciaram um alto percentual de eficácia em todos os tratamentos/dosagens utilizados, inclusive no controle positivo $(100,00 \%)$. Não houve necessidade de realizar análise estatística, pois não existiu variação dos resultados, todos apresentaram valores zero após a utilização dos tratamentos (Quadro 1). Os observados após a aplicação do ensaio in vitro na destruição de oocistos de Eimeria sp. demonstraram um maior percentual nas dosagens homeopáticas de $0,120 \mathrm{ml}: 0,800 \mathrm{ml} \mathrm{H}_{2} \mathrm{O}(47,06 \%)$ e no controle positivo $(50,98 \%)$, sendo considerados de baixa efetividade. $\mathrm{Na}$ análise estatística verificou-se que as médias de todos os tratamentos não diferiram significativamente à apresentada pelo controle negativo (Quadro 2).

Os valores encontrados após a aplicação do ensaio in vivo na redução da contagem de ovos nas fezes de Ascaridia sp. demonstraram após 12 dias de aplicação dos produtos, um alto percentual de eficácia em todos os tratamentos (100,00\%). A análise estatística comprovou que houve uma redução significativa entre as médias da contagem de ovos por grama de fezes antes e após a administração dos tratamentos $(p<0,05)$, mas não existiu uma diferença significativa entre as médias intertratamentos, inclusive com o controle negativo (Quadro 3). Os observados após a aplicação 
Quadro 1. Número de ovos viáveis e larvas recém-eclodidas de Ascaridia sp. (média geral de três repetições), encontrados após a aplicação dos tratamentos fitoterápico, homeopático, controle positivo e controle negativo, no ensaio in vitro, com suas devidas dosagens, e percentual de inibição de eclosão de ovos, quando comparado com o controle negativo

\begin{tabular}{|c|c|c|c|c|}
\hline \multirow[t]{3}{*}{ Tratamentos } & \multirow{2}{*}{\multicolumn{2}{|c|}{$\begin{array}{c}\text { Ascaridia sp. } \\
\text { (média geral de três repe- } \\
\text { tições } \pm \text { desvio padrão) }\end{array}$}} & \multirow{3}{*}{$\begin{array}{l}\text { Média total } \pm \\
\text { desvio padrão }\end{array}$} & \multirow{3}{*}{$\begin{array}{l}\text { Inibição de eclo- } \\
\text { são de ovos(\%) }\end{array}$} \\
\hline & & & & \\
\hline & $\begin{array}{c}\text { Ovos } \\
\text { viáveis }\end{array}$ & $\begin{array}{c}\text { Larvas } \\
\text { recém-eclodidas }\end{array}$ & & \\
\hline \multicolumn{5}{|l|}{ Fitoterapia } \\
\hline - $0,200 \mathrm{ml}$ produto $/ 0,800 \mathrm{ml} \mathrm{H}_{2} \mathrm{O}$ & 0 & 0 & 0 & 100,00 \\
\hline - $0,120 \mathrm{ml}$ produto $/ 0,880 \mathrm{ml} \mathrm{H}$ & 0 & 0 & 0 & 100,00 \\
\hline $\begin{array}{l}-0,060 \mathrm{ml} \text { produto } / 0,940 \mathrm{ml} \mathrm{H}_{2} \mathrm{O} \\
\text { Homeopatia }\end{array}$ & 0 & 0 & 0 & 100,00 \\
\hline - $0,200 \mathrm{ml}$ produto $/ 0,800 \mathrm{ml} \mathrm{H}_{2} \mathrm{O}$ & 0 & 0 & 0 & 100,00 \\
\hline - $0,120 \mathrm{ml}$ produto $/ 0,880 \mathrm{ml} \mathrm{H}_{2} \mathrm{O}$ & 0 & 0 & 0 & 100,00 \\
\hline $\begin{array}{l}\text { - } 0,060 \mathrm{ml} \text { produto/0,940 } \mathrm{ml} \mathrm{H}_{2} \mathrm{O} \\
\text { Controle positivo (Thiab./Meb.) }\end{array}$ & 0 & 0 & 0 & 100,00 \\
\hline $\begin{array}{l}\text { - } 0,010 \mathrm{ml} \text { produto } / 0,990 \mathrm{ml} \text { metanol } \\
\text { Controle negativo (água) }\end{array}$ & 0 & 0 & 0 & 100,00 \\
\hline - $1,000 \mathrm{ml} \mathrm{H} 2 \mathrm{O}$ & $116,7 \pm 14,8$ & 0 & $116,7 \pm 14,8$ & - \\
\hline
\end{tabular}

Quadro 2. Número de oocistos de Eimeria sp. (média geral de três repetições), encontrados após a aplicação dos tratamentos: fitoterápico, homeopático, controle positivo e controle negativo, no ensaio in vitro, com suas devidas dosagens, $\mathrm{e}$ percentual de destruição dos oocistos, quando comparado com o controle negativo

\begin{tabular}{|c|c|c|}
\hline \multirow[t]{2}{*}{ Tratamentos } & $\begin{array}{l}\text { Número de oocistos } \\
\text { após tratamentos }\end{array}$ & \multirow[b]{2}{*}{$\begin{array}{c}\text { Destruição dos } \\
\text { oocistos(\%) }\end{array}$} \\
\hline & $\begin{array}{l}\text { (média geral de três repe- } \\
\text { tições } \pm \text { desvio padrão) }\end{array}$ & \\
\hline \multicolumn{3}{|l|}{ Fitoterapia } \\
\hline - $0,200 \mathrm{ml}$ produto $/ 0,800 \mathrm{ml} \mathrm{H}_{2} \mathrm{O}$ & $633,3 \pm 76,4^{a^{*}}$ & 25,50 \\
\hline - $0,120 \mathrm{ml}$ produto $/ 0,880 \mathrm{ml} \mathrm{H}$ & $616,7 \pm 76,4^{\mathrm{a}}$ & 27,45 \\
\hline $\begin{array}{l}-0,060 \mathrm{ml} \text { produto } / 0,940 \mathrm{ml} \mathrm{H}_{2} \mathrm{O} \\
\text { Homeopatia }\end{array}$ & $633,3 \pm 152,8^{a}$ & 25,50 \\
\hline - $0,200 \mathrm{ml}$ produto $/ 0,800 \mathrm{ml} \mathrm{H}_{2} \mathrm{O}$ & $500 \pm 132,3^{\mathrm{a}}$ & 41,18 \\
\hline - $0,120 \mathrm{ml}$ produto $/ 0,880 \mathrm{ml} \mathrm{H}_{2} \mathrm{O}$ & $450 \pm 100,0^{\mathrm{a}}$ & 47,06 \\
\hline - $0,060 \mathrm{ml}$ produto $/ 0,940 \mathrm{ml} \mathrm{H}_{2} \mathrm{O}$ & $716,7 \pm 332,9^{a}$ & 15,69 \\
\hline Controle positivo (Thiab./Meb.) & & \\
\hline $\begin{array}{l}\text { - } 0,010 \mathrm{ml} \text { produto } / 0,990 \mathrm{ml} \text { metanol } \\
\text { Controle negativo (água) }\end{array}$ & $416,7 \pm 175,6^{\mathrm{a}}$ & 50,98 \\
\hline • $1,000 \mathrm{ml} \mathrm{H} 2 \mathrm{O}$ & $850 \pm 427,2^{\mathrm{a}}$ & - \\
\hline
\end{tabular}

do ensaio in vivo na redução da contagem de oocistos nas fezes de Eimeria sp. demonstraram após 12 dias de aplicação dos produtos, um maior percentual no produto homeopático $(60,33 \%)$, considerado pouco efetivo, com o controle positivo assumindo um percentual praticamente nulo $(2,07 \%)$. A análise estatística demonstrou que não houve uma redução significativa entre as médias da contagem de oocistos por grama de fezes antes e após a administração dos tratamentos, e nem entre as médias intertratamentos, inclusive com o controle negativo (Quadro 4).

\section{DISCUSSÃO}

No estudo in vitro o gênero Eimeria esteve mais presente, sendo neste ensaio poucos os nematóides observados, tendo apenas um gênero se apresentado, o Ascaridia. Grande foi o mérito do ensaio, pois não foram visualizados ovos e larvas desse nematóide, após os tratamentos, ape- nas contabilizou-se a presença dos oocistos de Eimeria. Inferindo então a respeito do ocorrido, podemos afirmar que obtivemos uma eficácia de 100,00\% sobre Ascaridia sp. em todos os tratamentos, naturais e químico.

Ao avaliar os dados referentes ao teste in vivo de redução da contagem de oocistos nas fezes de endoparasitos de Coturnix japonica, a eficácia ficou estabelecida em $42,05 \%$ no tratamento fitoterápico, $60,33 \%$ no homeopático, $2,07 \%$ no controle positivo e $50,21 \%$ no controle negativo. A análise estatística demonstrou a ausência de significância na redução entre os tratamentos e entre a comparação da redução inicial e final do opg de cada tratamento. Os dados demonstram que neste tipo de ensaio a homeopatia funcionou melhor para a espécie. Novamente enfatizamos a presença somente de oocistos de Eimeria sp., após realização do ensaio, não tendo se visualizado ovos de nematóides, o que foi observado no controle negativo, 
Quadro 3. Número médio de ovos de Ascaridia sp., por grama de fezes, no dia 0 , anterior à aplicação, e no dia 12, após a aplicação, dos tratamentos fitoterápico, homeopático, controle positivo e controle negativo, e percentual de redução da contagem de ovos nas fezes

\begin{tabular}{|c|c|c|c|c|}
\hline \multirow[t]{2}{*}{ Tratamentos } & \multicolumn{2}{|c|}{$\begin{array}{l}\text { Ovos por grama de fezes } \\
\text { (média de três repetições) }\end{array}$} & \multirow[t]{2}{*}{$\begin{array}{c}\text { Média } \\
\text { Intertratamentos }\end{array}$} & \multirow[t]{2}{*}{$\begin{array}{l}\text { Redução da contagem } \\
\text { de ovos nas fezes (\%) }\end{array}$} \\
\hline & Dia 0 & Dia 12 & & \\
\hline \multicolumn{5}{|l|}{ Fitoterapia } \\
\hline $\begin{array}{l}\text { - } 3 \mathrm{ml} \text { produto/diluídos em } \mathrm{H}_{2} \mathrm{O} / \\
\text { cada animal }\end{array}$ & 200 & 0 & $100^{\mathrm{a} *}$ & 100,00 \\
\hline \multicolumn{5}{|l|}{ Homeopatia } \\
\hline $\begin{array}{l}\text { - } 3 \text { ml produto/diluídos em } \mathrm{H}_{2} \mathrm{O} / \\
\text { cada animal }\end{array}$ & 100 & 0 & $50^{\mathrm{a}}$ & 100,00 \\
\hline \multicolumn{5}{|l|}{ Controle positivo (Thiab./Meb.) } \\
\hline $\begin{array}{l}\text { - } 0,300 \mathrm{ml} \text { do produto/oral/ } \\
\text { sem diluição/cada animal } \\
\text { Controle negativo }\end{array}$ & 100 & 0 & $50^{\mathrm{a}}$ & 100,00 \\
\hline - $\mathrm{H}_{2} \mathrm{O}$ pura & 150 & 100 & $125^{\mathrm{a}}$ & 33,34 \\
\hline $\begin{array}{l}\text { Média antes e após tratamentos } \\
\pm \text { desvio padrão }\end{array}$ & $137,5 \pm 47,0^{a}$ & $25 \pm 44,6^{b}$ & & \\
\hline
\end{tabular}

Quadro 4. Número médio de oocistos de Eimeria sp., por grama de fezes, no dia 0 , anterior à aplicação, e no dia 12, após a aplicação, dos tratamentos fitoterápico, homeopático, controle positivo e controle negativo, e percentual de redução da contagem de oocistos nas fezes

\begin{tabular}{|c|c|c|c|c|}
\hline \multirow[t]{2}{*}{ Tratamentos } & \multicolumn{2}{|c|}{$\begin{array}{l}\text { Oocistos por grama de fezes } \\
\text { (média três repetições) }\end{array}$} & \multirow[t]{2}{*}{$\begin{array}{l}\text { Média } \\
\text { Intertratamentos }\end{array}$} & \multirow[t]{2}{*}{$\begin{array}{l}\text { Redução da contagem de } \\
\text { oocistos nas fezes (\%) }\end{array}$} \\
\hline & Dia 0 & Dia 12 & & \\
\hline \multicolumn{5}{|l|}{ Fitoterapia } \\
\hline $\begin{array}{l}\text { - } 3 \text { ml produto/diluídos em } \mathrm{H}_{2} \mathrm{O} \text { / } \\
\text { cada animal }\end{array}$ & 9.000 & 5.216 & $7.108^{\mathrm{a} *}$ & 42,05 \\
\hline \multicolumn{5}{|l|}{ Homeopatia } \\
\hline $\begin{array}{l}\text { - } 3 \mathrm{ml} \text { produto/diluídos em } \mathrm{H}_{2} \mathrm{O} / \\
\text { cada animal }\end{array}$ & 23.400 & 9.283 & $16.341,5^{\mathrm{a}}$ & 60,33 \\
\hline \multicolumn{5}{|l|}{ Controle positivo (Thiab./Meb.) } \\
\hline $\begin{array}{l}\text { • } 0,300 \mathrm{ml} \text { do produto/oral/ } \\
\text { sem diluição/cada animal } \\
\text { Controle negativo }\end{array}$ & 3.250 & 3.183 & $3.216,5^{\mathrm{a}}$ & 2,07 \\
\hline - $\mathrm{H}_{2} \mathrm{O}$ pura & 8.200 & 4.083 & $6.141,5^{\mathrm{a}}$ & 50,21 \\
\hline $\begin{array}{l}\text { Média antes e após trata- } \\
\text { mentos } \pm \text { desvio padrão }\end{array}$ & $10.962,5 \pm 8.672,9^{a}$ & $5.441,3 \pm 2.692,8^{a}$ & & \\
\hline
\end{tabular}

* Médias de tratamentos seguidas por letras diferentes diferem significativamente entre si pelo teste de Tukey $(\mathrm{p}<0,05)$.

levando-nos a creditar grande eficácia dos produtos, alternativos ou positivo, quando do controle desses, inferindo em $100,00 \%$. Ao repararmos a baixa na eficácia do controle positivo concluímos que esta se deve ao produto convencional não ser indicado para controle de oocistos de Eimeria sp., assim como, ao estresse adquirido pelas aves, devido à administração via oral. Codornas são aves altamente estressadas e diversos fatores podem interagir com o lado psicológico acarretando em enfraquecimento de suas defesas contra patógenos. 0 alto valor de redução observado no controle negativo vem reafirmar que aves em cativeiro, sem estresse, bem cuidadas, com amplo espaço de circulação, boa alimentação, longe da presença de outras aves e animais, e seguindo todos os preceitos de higiene, o que foram pontos presentes na pesquisa, são fatores prioritários para redução natural de infecções (Oishi et al. 2003, Kushima et al. 2004, Bricarello et al. 2005, Jesus 2007, Veríssimo 2008, Muniz 2010).

De acordo com a classificação do índice de eficácia proposto pela World Association for the Advancement of Veterinary Parasitology (WAAVP), organização de onde provieram os ensaios in vitro e in vivo, um produto seria altamente efetivo se apresentasse mais de $90,00 \%$ de ação contra o parasita tratado, moderadamente efetivo quando atuasse entre 80,00 a $90,00 \%$, pouco efetivo quando a ação fosse entre 60,00 e $80,00 \%$ e não efetivo em níveis abaixo de 60,00\% (Powers et al. 1982, Brito et al. 2009). Dessa forma, podemos confirmar que pelos resultados alcançados, a planta $C$. ambrosioides é altamente eficaz no combate a nematóides de codornas em ensaios in vitro da inibição de eclosão de ovos, e em ensaio in vivo da redução de ovos nas fezes, afirmação que também pode ser creditada pela Organização Mundial da Saúde, que classifica um produto como eficiente acima de 80,00\% e Ministério da Agricultura do Brasil, acima de 75,00\% (Brasil 1990, Ministério Da Agricultura, Pecuária e Abastecimento 2007, WHO, 2007). 0 que não podemos afirmar com relação aos oocistos de Eimeria sp., cujo índice de eficácia esteve entre os parâme- 
tros de pouco a não efetivo, de acordo com as associações acima.

As técnicas utilizadas mostraram-se excelentes como métodos de diagnóstico para detecção e análise de eficácia ou resistência de produtos para endoparasitos intestinais de codornas. Nos casos em que se constatou a presença do gênero Eimeria, as técnicas utilizadas mostram-se mais eficientes que a necropsia, pois permite a detecção do parasito pela visualização dos oocistos, e evita o sacrifício das aves.

Deve-se ainda relacionar o resultado dos tratamentos com o estado físico do animal. As aves que foram tratadas com Chenopodium ambrosioides, seja na forma fitoterápica ou homeopática, na deposição em água, apresentaram aumento no ganho de peso, melhor aparência e maior postura, com cerca de 12,00 e $23,00 \%$ a mais na produção de ovos, frente ao produto controle positivo e controle negativo, respectivamente, sendo uma eficiente alternativa para profissionais e criadores que buscam uma melhor qualidade de vida para seus animais, produtos sem resíduos químicos, ambiente mais limpo e maiores ganhos financeiros.

A transposição da dose de $0,200 \mathrm{ml}$ do produto natu$\mathrm{ral} / 0,800 \mathrm{ml}$ de água, considerado de maior eficácia no controle dos endoparasitos no âmbito geral, para o ensaio in vivo, teve seu cálculo realizado encima do peso do alimento fornecido ao animal diariamente, isto é, quantidade do bolo fecal diário circulante. Essa medida foi necessária, visto a inviabilidade financeira da qual se tornaria o produto, caso sua dosagem fosse realizada pelo peso do animal, acompanhando o que estabelecia o fabricante do produto tradicional. Apenas seguimos a forma de administração recomendada pelo fabricante, que era duas vezes ao dia, durante três dias alternados. Não encontramos na literatura citada trabalhos que embasassem nosso planejamento, mas o mesmo surtiu efeito, pois nos resultados obtidos, observamos índices altamente efetivos na redução da contagem de ovos/oocistos, de acordo com a WAAVP (Powers et al. 1982), para Ascaridia sp., na forma homeopática $(100,00 \%)$ e fitoterápica $(100,00 \%)$.

\section{CONCLUSÕES}

Os principais gêneros de endoparasitos identificados na pesquisa foram Ascaridia e Eimeria.

Considerando os ensaios in vitro e in vivo observou-se uma eficácia anti-helmíntica da planta Chenopodium ambrosioides, tanto na forma homeopática, quando na fitoterápica, altamente satisfatória contra o nematóide Ascaridia sp., com índices de 100,00\%, acordando com padrões de eficácia da World Association for the Advancement of Veterinary Parasitology, World Health Organization e Ministério da Agricultura do Brasil.

Para o protozoário Eimeria sp., o índice de eficácia da planta, em qualquer forma, esteve abaixo do recomendado pelas mesmas organizações.

Os ensaios in vitro e in vivo realizados permitem confirmar a atividade anti-helmíntica de $C$. ambrosioides para nematóides de Coturnix japonica, o que possibilita a criação de novas alternativas para o controle das endoparasitoses aviárias.
Agradecimentos.- À Coordenação de Aperfeiçoamento de Pessoal de Nível Superior (CAPES).

\section{REFERÊNCIAS}

Albino L.F.T. \& Barreto S.L.T. 2003. Criação de codornas para produção de ovos e carne. Aprenda Fácil, Viçosa. 268p.

Back A. 2002. Manual de doenças de aves. Unioeste Editora e Gráfica Universitária, Cascavel. 245p.

Brasil 1990. Normas para produção, controle e utilização de produtos antiparasitários. Portaria no.90, de 4 de dezembro de 1989, Diário da República, Brasília, Seção 1, col. 2.

Bricarello P.A., Amarante A.F.T., Rocha R.A., Cabral Filho S.L., Huntley J.F., Houdijk J.G.M., Abdalla A.L. \& Gennari S.M. 2005. Influence of dietary protein supply on resistance to experimental infections with Haemonchus contortus in Ile de France and Santa Ines lambs. Vet. Parasitol. 134:99-109.

Brito D.R.B., Fernandes R.M., Lima M.Z., Fernandes C.M., Ferreira M.D.S., Rolim F.R.L. \& Silva Filho M.L. 2009. Atividade anti-helmíntica dos extratos aquoso e etanólico do fruto da Morinda citrifolia sobre Ascaridia galli. Revta Bras. Parasitol. Vet. 18(4):32-36.

Coles G.C., Bauer C., Borgsteede F.H.M., Geerts S., Klei T.R., Taylor M.A. \& Waller P.J. 1992. World association for the Advancement of Veterinary Parasitology (WAAVP) methods for the detection of anthelmintic resistance in nematodes of veterinary importance. Vet. Parasitol. 44:35-44.

Cubas Z.S. \& Godoy S.N. 2004. Algumas doenças de aves ornamentais. Canaril Almada, Portugal. 49p.

Fernandes M.Z.L.C.M., Fernandes R.M., Brito D.R.B. \& Borba H.R. 2009. Efeito anti-helmíntico dos extratos aquosos e etanólicos de Annona squamosa L. (fruta-do-conde) sobre o nematóide Ascaridia galli. Revta Bras. Plant. Med. 11(2):124-129.

Galvão P. \& Pereira K.K. 2011. Diagnóstico de possíveis focos de contaminação por parasitas em Ramphastideos do cativeiro da Faculdade Assis Gurgacz, Cascavel, PR. Thêma Sci. 1(2):156-159.

IBGE 2011. Produção da Pecuária Municipal. IBGE, Rio de Janeiro. 63p.

Jesus D.N.C. 2007. Avaliação dos efeitos da adição do óleo essencial de orégano (Origanum vulgare) na dieta, sobre a fisiologia e a produtividade de codornas japonesas (Coturnix coturnix japonica). Dissertação em Ciências Agrárias, Universidade de Brasília, Brasília, DF. 106p.

Kushima K., Yoshida K., Fujita M., Shigeta A., Horiuchi H., Matsuda H. \& Furusawa S. 2004. Chicken peripheral blood $\mathrm{CD}^{+}{ }^{+} \mathrm{CD} 4{ }^{-} \mathrm{CD} 8$ cells are regulated by endocrine and nerve systems. J. Vet. Med. Sci. 66(2):143-148.

Martins E.N. 2002. Perspectivas do melhoramento genético de codornas no Brasil. Anais I Simpósio Internacional de Coturnicultura, Lavras, MG, p.109-112.

McDougald L.R. 1997. Protozoa, p.865-883. In: Calnek B.W. (Ed.), Diseases of Poultry. 20th ed. Iowa State University Press, Iowa.

Ministério da Agricultura, Pecuária e Abastecimento 1997. Portaria no 48, de 12 de maio de 1997. Diário Oficial [da] República Federativa do Brasil, Brasília, DF, Seção 1, p.10165.

Ministério da Agricultura, Pecuária e Abastecimento 2007. Preconização para registro de acaricidas. Disponível em <http://www.agricultura. gov.br> Acesso em 15 mar. 2007.

Muniz C. 2010. Estresse nas granjas. Ciênc. Hoje. 46(273).

Oishi K., Nishio N., Konishi K., Shimokawa M., Okuda T., Kuriyama T. \& Machida K. 2003. Differential effects os physical and psychological stressors on immune functions of rats. Stress 6(1):33-44.

OPAS 2010. Manual veterinário de colheita e envio de amostras. PANAFTOSA/OPAS/OMS, Rio de Janeiro. 218p.

Powers K.G., Wood I.B., Eckert J., Gibson T. \& Smitc H.J. 1982. World Association for the Advancement of Veterinary Parasitology (WAAVP): guidelines for evaluating the efficacy of anthelmintics in ruminants (bovine and ovine). Vet. Parasitol. 10:265-284.

SBRT 2007. Dossiê técnico. Criação de codornas. Serviço Brasileiro de Respostas Técnicas, Brasília. 21p.

SEBRAE 2006. Ponto de Partida. Criação de codorna. Serviço Brasileiro de Apoio às Micro e Pequenas Empresas, Minas Gerais. 63p. 
Silva J.H.V., Jordão Filho J., Costa F.G.P., Lacerda P.B. \& Vargas D.G.V. 2011. Exigências nutricionais de codornas. Anais $21^{\circ}$ Congresso Brasileiro de Zootecnia, Maceió, AL, p.1-15.

Vercruysse J., Holdsworth P., Letonja T., Barth D., Conder G., Hamamoto K. \& Okano K. 2001. International harmonization of anthelmintic efficacy guidelines (Part 1). Vet. Parasitol. 96:171-193.

Veríssimo C.J. 2008. Alternativas de controle da verminose em pequenos ruminantes. Instituto de Zootecnia, Agência Paulista de Tecnologia dos Agronegócios, Secretaria de Agricultura e Abastecimento do Estado de São Paulo, Nova Odessa. 127p.
Vicente J.J., Rodrigues H.O., Gomes D.C. \& Pinto R.M. 1995. Nematóides do Brasil. IV. Nematóides de aves. Revta Bras. Zool. 12(1):1-273.

Vieira S. 2008. Introdução à Bioestatística. Elsevier, Rio de Janeiro. 345 p.

Vita G.F., Ferreira I., Costa Pereira M.A.V., Azevedo J.R., Sanavria A., Barbosa C.G., Gallo S.S.M. \& Vasconcellos H.V.G. 2014. Eficácia de Chenopodium ambrosioides (erva-de-santa-maria) no controle de endoparasitos de Gallus gallus (galinha caipira). Pesq. Vet. Bras. 34(1):39-45.

WHO 2007. Atividade carrapaticida: resistência e susceptibilidade a drogas. Disponível em <http://www.who.com> Acesso em 10 jan. 2007. 